Bond University

Research Repository

\title{
Should BIPV technologies be empowered by innovation policy mix to facilitate energy transitions? - Revealing stakeholders' different perspectives using $Q$ methodology
}

Chang, Ruidong; Cao, Yuan; Lu, Yujie; Shabunko, Veronika

Published in:

Energy Policy

DOI:

10.1016/j.enpol.2019.02.047

Licence:

CC BY-NC-ND

Link to output in Bond University research repository.

Recommended citation(APA):

Chang, R., Cao, Y., Lu, Y., \& Shabunko, V. (2019). Should BIPV technologies be empowered by innovation policy mix to facilitate energy transitions? - Revealing stakeholders' different perspectives using $Q$ methodology. Energy Policy, 129, 307-318. https://doi.org/10.1016/j.enpol.2019.02.047

\section{General rights}

Copyright and moral rights for the publications made accessible in the public portal are retained by the authors and/or other copyright owners and it is a condition of accessing publications that users recognise and abide by the legal requirements associated with these rights.

For more information, or if you believe that this document breaches copyright, please contact the Bond University research repository coordinator. 


\title{
Should BIPV technologies be empowered by innovation policy mix to facilitate energy transitions? - Revealing Stakeholders' different perspectives using $Q$ methodology
}

\section{Ruidong Chang ${ }^{1,}$, Yuan Cao ${ }^{2}$, Yujie Lu ${ }^{3, *}$, and Veronika Shabunko ${ }^{4}$}

\begin{abstract}
As new renewable energy applications, building-integrated photovoltaics (BIPV) systems have significant potential to facilitate energy transitions towards renewable energy in highly urbanized countries, where large areas of land for developing large-scale solar or wind farms are limited. Government policy plays a significant role in nurturing and protecting energy innovations at the early development stage, such as BIPV. However, various actors could have divergent views on the policies for energy innovations, and policymakers need to consider these views in policymaking to avoid potential failures in policy implementation. By taking BIPV as an example, this study aims to reveal stakeholders' different perspectives on the required innovation policies for new energy technologies based on Q methodology. The results indicate even though stakeholders share similar views on some aspects of BIPV policies, four significantly distinct policy perspectives on BIPV exist in stakeholders' mindsets, including supervisory support, intensively investigate, cautiously stimulate and proactively promote. These policy perspectives require significantly different approaches to promote BIPV, which indicates the complexity in formulating one set of policy mix catering for the various mindsets of stakeholders. This study has both theoretical contributions to innovation policy mix for energy transitions, and policy implications for promoting energy innovations, especially BIPV worldwide.
\end{abstract}

Keywords: Renewable energy; Solar power; Sustainability transition; Energy transition; Energy policy; Innovation policy

\footnotetext{
${ }^{1}$ Centre for Comparative Construction Research, Faculty of Society and Design, Bond University, 14 University Dr, Robina, Queensland 4226, Australia

2 Department of Civil Engineering, University of Toronto, 35 St. George Street, Toronto, ON M5S 1A4, Canada

${ }^{3}$ Department of Building Engineering, College of Civil Engineering, Tongji University, 200092, China (Corresponding author, E-mail: lu6@tongji.edu.cn)

${ }^{4}$ Solar Energy Research Institute of Singapore, 7 Engineering Drive 1, \#06-01 Block E3A, Singapore 117574
} 


\section{Introduction}

As an important application of solar energy in urbanized areas where there are many high-rise buildings, the integration of PV into building components, such as façades, is known as building-integrated photovoltaics (BIPV) which has significant potential (Pagliaro et al., 2010). Over the last few decades, the BIPV market has started to bloom with global BIPV installed capacity of 2.3 GW in 2015 (Tabakovic et al., 2017). Dominating countries for accelerated deployment of BIPV technologies are Europe, follow up by United State of America (USA) and Asia-Pacific with total installed capacity in 2015 over 967 MW, 476 MW, and 492 MW, respectively (Global Industry Analysts, 2015). Such swift adoption of BIPV technologies on a global scale is driven by increasing concerns of total building energy intensities and related $\mathrm{CO}_{2}$ emissions, stringent regulations and national goals towards 2-degree C trajectory (International Energy Agency, 2017), coupled with the continuous decreasing price for PV devices and the increasing technical performance.

BIPV technology is very promising in facilitating the transition of the energy systems towards renewable energy in many urbanized countries, such as Singapore, where a large area of land for deployment of solar farms is simply not available. However, there are still many barriers to the development of BIPV (Heinstein et al., 2013). Firstly, although the price of PV panels has dropped over the years (Zomer et al., 2016), the total installation cost of BIPV system is still high, as the system consists of many components (Sozer \& Elnimeiri, 2007). The uncertain financial payback period because of the high cost hindered stakeholders to adopt BIPV systems. For instance, the payback period of BIPV systems is estimated to be as long as 53 years without any government support or subsidies (Hammond et al., 2012). Furthermore, the BIPV technology is still a somewhat new application of solar power and previous studies have identified some technical issues related to performance efficiency (Azadian \& Radzi, 2013; Maturi et al., 2014; Zomer et al., 2016), design and installation (Aristizabal \& Gordillo, 2008; Azadian et al., 2013; Ferrara et al., 2016) as well as the maintenance process (Peng et al., 2011; Yang, 2015). Moreover, the successful adoption of BIPV requires close collaboration (Cumming et al., 2017) and knowledge-sharing among multiple stakeholders (Zeeuw, 2011). However, the current stakeholders' awareness and confidence level of BIPV technologies are low due to the financial and technical problems (Lim et al., 2009). Because of these barriers, it remains unclear whether BIPV technology could gain momentum and becomes a mainstream approach of energy generation in the future.

Given the numerous barriers to the utilization of BIPV systems, various previous studies indicated that government policy plays a critical role in eliminating the barriers to BIPV technology so that BIPV technology could become a serious option for enterprises. In term of the financial barrier, Azadian \& Radzi (2013) indicated that the government should launch more supportive policies and provide more financial aids to encourage further R\&D activities to lower the cost of BIPV and shorten the payback period (Azadian et al., 2013). Similarly, Yang (2015) proposed that support schemes from the government could eliminate the technical barriers and advance the performance of BIPV systems (Yang, 2015), and governmental efforts, including developing demonstration projects and economical supportive policies, could tackle the lack of awareness and confidence among various stakeholders 
(Pagliaro et al., 2010; Yuan et al., 2013). Lu et al. (2018) indicated that the government could establish a regulatory framework to support solar power using crowdfunding.

However, even though the role of government policy in tackling the barriers to BIPV has been discussed, there are several major gaps of knowledge exist in the study of government policy on BIPV technologies. Firstly, before issuing supporting policies to BIPV, the government needs to make sure that BIPV technology has significant potential and could facilitate the energy transition of the country, and thus deserves to be invested and supported by government policies. However, currently, it remains unclear how industry practitioners and experts perceive the potential of BIPV technology.

Moreover, there is lack of theoretical frameworks applied in the policy studies on BIPV. The uptake of BIPV technologies is a very complex process. It not only needs the technological maturity and improving the financial performance of the BIPV technology itself, but also requires the market opportunities and improved infrastructures for the technology from both the building and energy sector, which could be very difficult as it needs to compete with the dominant fossil fuel energy technologies and systems. Therefore, a holistic policy system supporting BIPV need to have various functions, to not only strengthen the performance of BIPV itself but also weaken the existing fossil-fuel energy regime to provide market opportunities for BIPV technologies. However, previous studies on BIPV policies almost solely focuses on the technological and economic factors of BIPV without systemically investigating the various potential factors, such as market formation, resource mobilisation and decreased support for regime technologies, that need to be responded by the different policy functions. Furthermore, the strong collaboration among different stakeholders is the cornerstone of the successful implementation of BIPV technology (Lim et al., 2009). This again requires an understanding of the various stakeholder groups' opinions and perceptions of BIPV to identify the similarities and differences between stakeholders' perspectives on the required policies to support BIPV, so that stakeholder collaboration could be fostered.

To respond to the above gaps of knowledge, this study employs Q methodology to identify and examine the different BIPV stakeholders' perspectives of BIPV development from an innovation policy mix perspective in the context of Singapore, which is an urbanized country that is keen to promote BIPV technology. The exponential growth of the share of solar technologies starting from 2009, having reached 71MWp by the end of 2016, can help Singapore to achieve its 2030 carbon mitigation target and accelerate penetration of solar application to 4GW by 2030 (Solar Energy Research Institute of Singapore, 2018).

This study provides references for policymakers and industry practitioners to better understand the role of BIPV in shaping energy transitions. The specific research aims are as follows.

1) Identify the statements related to the prospects of and policy functions for BIPV development based on the innovation policy mix perspective

2) Identify the major types of stakeholder perspectives on the prospects of and policy functions for BIPV through analyzing stakeholders' ratings on the statements

3) Propose theoretical and policy implications for better understanding and guiding the development of BIPV 


\section{Innovation policy mix for sustainability transitions}

With the global consensus of transitioning towards a sustainable future, the concept of sustainability transitions gains momentum. Sustainability transition is commonly defined as '...long-term, multi-dimensional, and fundamental transformation processed through which established socio-technical systems shift to more sustainable alternatives' (Markard et al., 2012). The main approach to analyze sustainability transition is the multi-level perspective (MLP), which was first proposed by Rip and Kemp (1998) and further developed by Geels (2002). The MLP indicates transitions are influenced by factors from three levels, namely niche, regime and landscape (Geels, 2002).

Niches are defined as the 'protective space' where the sustainability-related movements occur and where the time-limited shelter is provided to protect the novelties from the selection rules of the existing market (Lachman, 2013). Regimes represent the prevailing regulations and routines of the existing systems, which prevent the uptake of sustainability innovations, e.g. BIPV, and are highly resistant to changes (Geels, 2004; Grin et al., 2010). Landscape refers to the broader context influencing the level of niches and regimes, for example, climate change (Lachman, 2013; Rip et al., 1998). According to MLP, sustainability transitions take place as a result of the interplay of the three levels. Landscape factors create pressure and weaken regimes while niches accumulate impetus to evolve and eventually break into the mainstream of the existing system (Geels, 2006; Grin et al., 2010). Therefore, niche plays an essential role in the MLP framework as it serves as the 'seeds' for successful sustainability transitions (Chang et al., 2017b).

However, as pointed out by Kemp et al. (1998), innovative niches need to overcome various barriers to take over the incumbent position of the existing regimes, especially in the early stage of development. For instance, most innovations are relatively crude with many uncertainties and usually come with a higher price compared to those widely adopted technologies, which could easily lead to negative perceptions to potential users (Xue et al., 2016). Without the protection and promotion from the government, the development of innovative niches could be hindered or even fail entirely at the infant stage.

Innovation policy refers to the actions launched by the government or public organizations that affect the innovation processes. Innovation policy instruments can be categorized into three major types, namely regulatory instruments, economic instruments and soft instruments (Borrás \& Edquist, 2013). Innovation policy mix involves the use of multiple policy instruments at various policy dominions to address the problems identified (Quitzow, 2015a). Previous studies have examined innovation policy mix used to support energy niches. Van Eijck and Romijn (2008), for instance, analyzed the development process of the Jatropha biofuels in Tanzania under the influences of governmental support policies (Van Eijck et al., 2008). Verbong et al. (2010) discussed the biomass gasification in India supported by regulations and government funding (Verbong et al., 2010). Zhao et al. (2016a) studied the barriers to the further development of wind power in China based on a social-technical transition perspective. Regarding solar power, Lilliestam et al. (2018) examined three sets of policy instruments supporting concentrating solar power, namely feed-in tariffs or auctions, risk coverage support, and demonstration projects. Chen and Wei (2018) examined the incentive policy for solar photovoltaic 
community microgrid in China. Innovation policies have also been studied in various areas such as alternative fuel vehicles (Kwon, 2012), and sustainable construction (Chang et al., 2016).

There are also some theoretical studies on innovation policy mix. For instance, Magro and Wilson (2013) proposed a framework for evaluating an innovation policy mix and used a case study of Basque Country region of Spain to demonstrate the evaluation framework. Lanahan and Feldman (2015) explored the notion of multilevel innovation policy mix and used the case of U.S. small business innovation research programs to demonstrate the interactions between multiple levels of innovation policy mixes. Rogge and Reichardt (2016) proposed an extended policy mix concept for sustainability transition and illustrated the concept by using German renewable energy policy as an example. Other studies investigating policy mix include Kivimaa et al. (2017) who investigated the creative destruction of regime through policy mixes and Falcone et al. (2017) who analyzed policy mixes for sustainability transition under crisis scenarios.

Even though these previous studies have provided some insights on innovation policy mix for sustainability transitions, there is a lack of theoretical frameworks that demonstrate the required policy functions needed to systemically empower sustainability niches. Indicted by the MLP, the interplay of the niche, regime and landscape influence the outcome of whether sustainability niches could gain momentum and become widely accepted (Chang et al., 2015). Therefore, innovation policy mix should have various functions to not only provide support for niches, but also destabilise the regimes to provide opportunities for the niches (Alkemade et al., 2011; Meelen \& Farla, 2013; Weber \& Rohracher, 2012). Few empirical studies on innovation policy mix investigate the various policy functions required for sustainability niches. Responding to this gap of knowledge, Kivimaa and Kern (2016) provided an insightful analysis of the policy functions required to support niche innovations by proposing the analytical framework of policy mixes for sustainability transition through creative destruction, as shown in Table 1. In the analytical framework, the functions of 'Creative' and 'Destruction' are further classified into seven (C1-C7) and four (D1-D4) sub-functions respectively to provide detailed guidance for the innovation policy mix. This study utilized above-mentioned analytical framework as the theoretical basis.

Table 1.

The analytical framework of policy mixes for sustainability transition

\begin{tabular}{lll}
\hline Main functions & Number & Sub-functions \\
\hline & C1 & Knowledge creation, development and diffusion \\
& C2 & Establishing market niches/market formation \\
Creative & C3 & Price-performance improvements \\
(niche support) & C4 & Entrepreneurial experimentation \\
& C5 & Resource mobilisation \\
& C6 & Support from powerful groups/legitimation \\
& C7 & Influence on the direction of search \\
& D1 & Control Policies \\
Destruction & D2 & Significant changes in regime rules \\
(regime destabilisation) & D3 & Reduced support for dominant regime technologies \\
& D4 & Changes in social networks, replacement of key actors \\
\hline
\end{tabular}

Analyzing the needed policy functions for BIPV from stakeholders' perspective is particularly important for the development of BIPV as currently there is lack of effective government policies 
specifically for promoting BIPV. There are supporting policies for PV applications in buildings in general. For instance, China has utilized various approaches including R\&D incentives, fiscal and tax incentives, and grid-connection incentives to promote PV applications in buildings. In 2009, China implemented the Golden Sun Demonstration Program which provides subsidies of 50\% of the total costs for grid-connected PV systems larger than $300 \mathrm{~kW}$ and issued various regulations in the following years to regulate this program such as the Notice on Implementing the Golden Sun Demonstration Buildings issued in 2012 (Zhao et al., 2016b). Similarly, in Singapore, the Economic Development Board and Housing \& Development Board (HDB) launched the SolarNova program in 2014 to promote the deployment of PV systems across the assets of government agencies and HDB blocks (Housing \& Development Board, 2018). In Germany, the cooperative R\&D efforts for solar panels have been boosted by initiatives such as the "Solar Valley Mitteldeutschland" and "Innovationsallianz Photovoltaik” (Quitzow, 2015b). However, all these supporting policies and programs are for PV in general, and very few polices were issued specifically to promote BIPV. To facilitate the policymaking process for BIPV, it is important to identify the required policy functions perceived by various stakeholders of BIPV.

\section{Methodology}

Q Methodology is a scientific model to study human subjectivities in a systemic and structured manner (Brown, 1996; Eden et al., 2005). Q Methodology was initially applied to the field of psychology studies and was later diffused in other disciplines to examine stakeholders' discourses on a specific subject (Brown, 1996; Eden et al., 2005). The uniqueness of Q methodology is to explore the trends within and across individuals (Barry \& Proops, 1999), which focuses on the process of discovery instead of pre-determining what should exist (Kim \& Lee, 2015). Q methodology has been widely adopted in various fields, for instance, to identify stakeholder's perspectives in flood management (Raadgever et al., 2008), and to map the various opinions among stakeholders on the management of mangrove (Hugé et al., 2016). Additionally, Q methodology was employed in studies that specially target on the policies related to the planning and implementation of renewable energy sources such as wind and biomass (Breukers, 2006; Cuppen et al., 2010; Ellis et al., 2007). However, the application of Q methodology to the renewable energy sector is still considered rare. This study employs Q methodology to identify stakeholders' perceptions on BIPV.

\subsection{Identification of $Q$ sample}

The first step of the Q methodology is the construction of concourses, also known as Q population, to reflect the various viewpoints on the focused subject, which in this study is the prospects and policy functions supporting BIPV in Singapore. Once the pool of statements was established, duplicate and trivial items were then be removed. A total number of 40 concourses were collected from extensive literature reviews, which were identified through keyword-based library search in the title, including 'BIPV', 'policy' and 'Singapore'. Following Cuppen et al. (2010), when collecting the statements, changes to the original wording were kept at a minimum so that the nuance and implications behind each statement would prevail (Cuppen et al., 2010).

The 40 statements were strategically categorized into 12 sections base on the aforementioned analytical 
framework of innovation policy mixes proposed by Kivimaa et al. (2016), while an additional category

(P) was added to the framework to better understand each stakeholder's judgments of BIPV's prospect

in Singapore. The 40 statements were piloted by 6 researchers, as recommended by Brown et al. (2015).

The six researchers have abundant research experience in renewable energy techniques or policies for

the built environment. Among them, two researchers hold senior positions at the Energy Studies

Institute, National University of Singapore, and these two researchers are experts in renewable energy

policy for the built environment. The other four researchers are all senior scientists from the Solar

Energy Research Institute of Singapore. Based on the feedback received, slight modifications were

made to a few ambiguous statements and an addition of 4 statements was included, which resulted in a

finalized list of 44 statements, as presented in Table 2.

\section{Table 2.}

Q samples

\section{Statements}

\section{Prospects of BIPV in Singapore (P)}

1. BIPV will not become mainstream practice in Singapore due to its low energy conversion efficiency.

2. BIPV will not become mainstream practice in Singapore as Singapore does not have enough sunshine (e.g. rainy, cloudy weather and low irradiance on the facade), and thus BIPV generates very intermediate energy.

3. BIPV will not become mainstream practice as currently solar energy is a very small proportion $(<1 \%)$ of total generation, with $95 \%$ of electricity generation being from natural gas.

4. BIPV is the best form to utilize solar energy in Singapore because Singapore has limited land resources for the large-scale solar farm.

5. Singapore needs BIPV because it is the only kind of available renewable energy that can replace some portion of electricity generation from natural gas.

Knowledge Creation, Development and Diffusion (C1)

6. R\&D capability of BIPV in Singapore is weaker compared to developed countries (e.g. Germany).

7. Lifecycle benefits/costs of BIPV should be investigated to facilitate decision-making.

8. Singapore does not need to invest much in R\&D of BIPV because there is a wide availability of BIPV technologies globally

9. Singapore government should establish a comprehensive R\&D funding scheme or subsidies on BIPV for the industry.

10. The energy conversion efficiency of BIPV panel is not high enough (e.g. 11\%), and we should wait some time for technology improvements before wide application.

11. Singapore government shall promote demonstration projects and provide education programs to motivate the industry about BIPV.

12. Singapore government should issue industry standards and codes for BIPV.

Establishing Market Niches/Market Formation (C2)

13. People are reluctant to purchase/invest in innovative buildings with BIPV systems as they are normally more expensive than similar buildings (without BIPV systems).

14. Buildings with BIPV systems have a potentially large market value as they can generate electricity on-site, which reduces operational cost in the long run.

15. Singapore government shall create customer demand of BIPV by establishing BIPV labeling certificate, and provide a tax exemption for developers adopting BIPV in their projects, etc.

16. Buildings with BIPV systems have a potentially large demand as Singapore has a large group of residents who have highly increased environmental awareness and wealth, thus willing and able to purchase "green" projects despite the higher price.

Price-performance Improvements (C3)

17. Singapore does not need to develop the manufacturing industry of BIPV modules, as high-quality and low-price modules already exist in the global market, which we can just import to the local market.

18. Singapore government needs to provide subsidies for domestic BIPV manufacturers, to help them lower the product price thereby diffusing BIPV in the market more rapidly.

Entrepreneurial Experimentation (C4)

19. Singapore should stimulate entrepreneurship and bankability of small and medium-size firms in BIPV by providing low-interest loans, and venture capital.

20. In Singapore, there are only a few choices for BIPV products (e.g. opaque, semi-transparent) due to limited numbers of local BIPV companies/distributors. The government should encourage entrepreneurship and experimentation to diversify the products (e.g. transparent/colorful PV panels). 


\section{Resource Mobilization (C5)}

21. Singapore government shall establish an information platform of BIPV, e.g. providing reference guidelines for the best available technology of BIPV for the industry.

22. Banks are not willing to provide support for projects with BIPV systems, as it may involve high risks.

23. There is a lack of talents with BIPV experience in the industry, and thus universities should offer more renewable energy-related degrees and graduate more young professionals with BIPV expertise.

Support from powerful groups/legitimation (C6)

24. Projects with BIPV systems face great difficulties in obtaining governmental approvals (e.g. from different agencies).

25. Corporate leaders' opinions on BIPV are crucial for BIPV adoption, and thus persuading corporate leaders on the importance of BIPV is necessary.

26. As an influential player in the development of public housing, HDB should take a more proactive attitude to promote BIPV.

27. Singapore statutory boards (e.g. BCA) should take more proactive attitude and actions to promote BIPV.

28. Private developers, such as CapitaLand, should take a more proactive attitude to adopt BIPV.

Influence on the direction of search (C7)

29. Singapore government should release clear signals of BIPV for the industry, clarifying the government's vision and strategic planning of BIPV.

30. Singapore government needs to conduct a detailed potential analysis of BIPV to know how much solar power could be harvested.

31. Singapore government needs to establish an explicit target of energy portfolio standard for renewable energy (e.g. 5\% of solar energy) in the long term.

\section{Control policies (D1)}

32. In view of the recently announced carbon tax from 2019, Singapore should impose a higher penalty e.g. 20 dollars/t on greenhouse gas emissions.

33. In the long run, Singapore should gradually reduce the dependence on natural gas because someday natural gas will run out in the world.

34. It is not practical to phase out natural gas in Singapore, as there is not enough renewable energy resource (including BIPV) that could provide the whole electricity generation in Singapore.

35. It is not practical to implement control policies like the recently announced carbon tax to restrict natural gas because it may increase electricity price and cause social unhappiness.

Reduced support for dominant regime technologies (D2)

36. Singapore should withdraw support for traditional electricity sources e.g. natural gas through cutting relevant $R \& D$ funding.

Significant changes in regime rules (D3)

37. Singapore should implement total liberalization of the electricity market, which will take effect in 2018, allowing households to sell the electricity generated by BIPV to the grid.

38. Singapore should require the mandatory installation of BIPV on new residential buildings.

39. Singapore should establish stronger energy efficiency policies for the industry e.g. zero energy buildings, so that BIPV will become a serious option for industries.

40. Imposing smart meters in households will increase the awareness of building occupants/owners in monitoring the export of potential of BIPV to the grid.

41. The Green Mark standard should increase the points for using BIPV.

Changes in social networks, replacement of key actors (D4)

42. Singapore government has made significant progress to promote renewable energy, and there is no need to conduct structural changes in the government (e.g. establishing an interagency committee specifically focusing on renewable energy).

43. Allow key players of BIPV to participate more in the decision-making process of energy policy and to interact more with the government.

44. The government should provide avenues to disseminate knowledge and skills of BIPV to the stakeholders involved in the conventional energy market.

\subsection{Selection of P-set}

The Q method follows Stephenson's small sample principle as the respondents are actually the variables in Q methodology (Hugé et al., 2016), and snowball sampling is a common method in Q methodology to identify the respondents (Kim et al., 2015). Specifically, regarding the number of respondents, as Q methodology aims to identify diverse viewpoints and perspectives (Dryzek \& Niemeyer, 2008), the selection of participants (P-set) should be based on the varied perspectives rather than quantity (Howard et al., 2016). Q methodology relies on a representative breadth of viewpoints 
rather than the representative number of people, and studies employing Q methodology normally has a sample size of 10 to 30 respondents, such as 12 respondents in Silvius et al. (2017) and 19 respondents in Jaung et al. (2016). Regarding the sampling method, snowball sampling has been utilized to identify respondents in various studies employing Q methodology such as Kim et al. (2015) and Hugé et al. (2016).

In this study, participants from four distinct BIPV stakeholder groups, including local authorities, building developers, designers, and PV manufacturers, were contacted and selected firstly to reflect a wide range of expertise and interests. Next, following previous Q methodology studies, the snowball-sampling approach was adopted to enlarge the P-set, which means those previously identified participants were requested to refer other participants with experience in BIPV. As a result, a list of 15 participants was finalized, as shown in Table 3. In summary, four participants were from the "PV Manufacturer” group, six from "Designer" group, three from "Developer" group and two from "Statutory Board" (the government) group.

\section{Table 3.}

Profile of the Q samples

\begin{tabular}{lllr}
\hline ID & Category Group & Position & Years of experience in BIPV \\
\hline 1 & Manufacturer & Director & $3-5$ years \\
2 & Manufacturer & Senior director & $3-5$ years \\
3 & Designer & Director & $6-10$ years \\
4 & Statutory Board & Department head & $1-2$ years \\
5 & Designer & Senior director & $6-10$ years \\
6 & Designer & Senior executive & $3-5$ years \\
7 & Designer & Director & $1-2$ years \\
8 & Developer & Senior executive & $6-10$ years \\
9 & Designer & Senior designer & $3-5$ years \\
10 & Statutory Board & Department head & $6-10$ years \\
11 & Designer & Director & $3-5$ years \\
12 & Manufacturer & Executive engineer & $6-10$ years \\
13 & Developer & Director & $1-2$ years \\
14 & Developer & Manager & $1-2$ years \\
15 & Manufacturer & Senior engineer & $3-5$ years \\
\hline
\end{tabular}

\subsection{Exercise of Q-sorting}

The data collection process, namely Q sorting in Q methodology, was performed through 15 face-to-face interviews with the identified 15 respondents from May to October 2017. Each interview took 60 to 90 minutes. The major agenda for the interview was to instruct participants to rank the Q sample in an order based on a forced quasi-normal contribution, as shown in Fig. 1, followed by exit interview questions.

The 44 statements were printed on separate shuffled cards (one statement for one card) and provided to participants. The participants were then asked to place the statement cards onto different sections of two Q-boards. The primary Q-board was divided into three sections, namely 'agree', 'neutral' and 'disagree', and each section allowed 17, 10 and 17 statements respectively. Next, the participants were instructed to further transfer the statements onto the secondary Q-board, which consisted of 7 sections. The 'agree' section and 'disagree' section from the primary Q-board were each separated into 'strongly agrees/disagrees', 'moderately agree/disagree' and 'slightly agree/disagree', each with the space available for 3, 6 and 8 statements. 
After the Q-sorting was completed, a short exit interview was conducted. The participants were asked to give justifications about the statements that they had placed on the two extremes, that is, strongly agreed and strongly disagreed statements. The information obtained from the exit interview would assist the researchers with the interpretation of results. The next two steps of Q methodology, namely 'factor analysis' and ' results interpretation', will be presented in the subsequent 'Result' section.

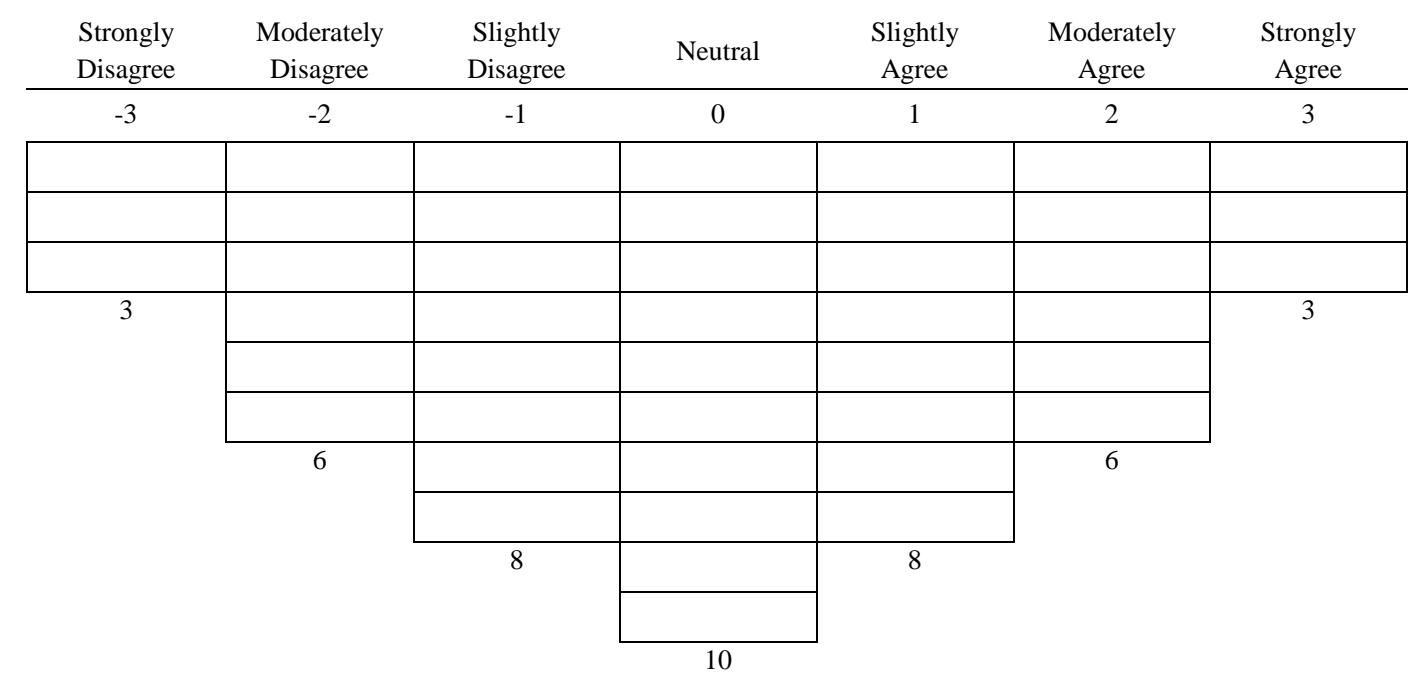

Fig. 1. Quasi-normal distribution

\section{Results}

\subsection{Factor analysis}

After the data was collected through the process of Q-sorting, factor analyses were performed on PQMethod, version 2.35, which is a statistical program that specially designed for Q methodology to conduct factor analyses (Schmolck \& Atkinson, 2014).

\subsubsection{Factor extraction and rotation}

Firstly, a principal component factor analysis (PCA) was carried out and eight unrotated factors were extracted. In Q methodology, a factor is a technical term for a group of participants who share the similar viewpoints. In this study, participants sharing the similar perspectives towards the deployment of BIPV in Singapore will be loaded into the same factor. Only the factors with an eigenvalue greater than 1 are qualified as significant and therefore worth being further analyzed (Kaiser, 1960). In this study, there are four factors with an eigenvalue greater than 1 , and they were selected and proceeded to the next step of the analysis.

The four chosen factors were rotated through Varimax rotation to maximize the amount of explained variance without affecting consistency (Van Exel \& De Graaf, 2005). After rotation (Table 4), three participants had significant factor loadings in more than one factor (ID: 9, 13, 15), which were considered confounded and therefore excluded from the later analysis. The remaining 12 participants together explained $63 \%$ of the overall variance and defined the characteristics of the four factors. 
Table 4.

Rotated Factor Matrix with factor characteristics

\begin{tabular}{|c|c|c|c|c|c|}
\hline Category Group & ID & Factor 1 & Factor 2 & Factor 3 & Factor 4 \\
\hline Manufacturer & 1 & 0.1065 & -0.2845 & -0.1931 & 0.7555 \\
\hline Manufacturer & 2 & -0.1803 & 0.4491 & 0.2336 & 0.5681 \\
\hline Manufacturer & 12 & 0.3115 & 0.2847 & 0.1281 & 0.7383 \\
\hline Designer & 3 & 0.3978 & 0.5226 & -0.0488 & -0.2943 \\
\hline Designer & 5 & 0.2373 & 0.1848 & 0.4073 & 0.0500 \\
\hline Designer & 6 & 0.2466 & 0.4708 & 0.1043 & 0.2343 \\
\hline Designer & 7 & -0.0498 & -0.1804 & 0.8655 & 0.0234 \\
\hline Designer & 11 & 0.7174 & 0.1285 & 0.2056 & 0.2570 \\
\hline Statutory Board & 4 & -0.0232 & 0.8249 & -0.0281 & 0.0493 \\
\hline Statutory Board & 10 & 0.2159 & 0.7158 & 0.1999 & 0.0704 \\
\hline Developer & 8 & 0.2526 & 0.3443 & 0.7501 & 0.1540 \\
\hline Developer & 14 & 0.8797 & 0.0675 & -0.0174 & 0.0725 \\
\hline Designer* & 9 & -0.2407 & 0.6064 & 0.6029 & -0.1469 \\
\hline Developer* & 13 & 0.3131 & 0.4455 & 0.2760 & 0.1851 \\
\hline Manufacturer* & 15 & 0.4536 & 0.1741 & 0.3673 & 0.5735 \\
\hline Explained variance (\%) & & 15 & 19 & 15 & 14 \\
\hline Number of defining variables & & 2 & 4 & 3 & 3 \\
\hline Average relative coefficient & & 0.800 & 0.800 & 0.800 & 0.800 \\
\hline Composite reliability & & 0.889 & 0.941 & 0.923 & 0.923 \\
\hline Standard error of factor scores & & 0.333 & 0243 & 0.277 & 0.277 \\
\hline
\end{tabular}

Note: Stakeholders noted by * have significant factor loadings in more than one factor

\subsubsection{From factors to perspectives}

After the four factors were identified, the weighted average score (Z-score) of each statement was calculated by first applying different weights for each statement according to the statement's factor loading. Next, the calculated weighted average factor scores were standardized so that every factor score has the same mean and standard deviation. By doing so, the Z-scores are comparable across factors. Based on the calculated Z-scores, the factor array for each factor could be generated (Fig. 2). Factor array is the prototype sort for each factor that represents the general combined views of the specific group of participants. Based on the factor array, the stakeholders' opinion towards BIPV could be identified. The final factors were then summarized into four perspectives, namely, 'Supervisory Support'; 'Intensively Investigate'; 'Cautiously Stimulate'; and 'Proactively Promote'. 


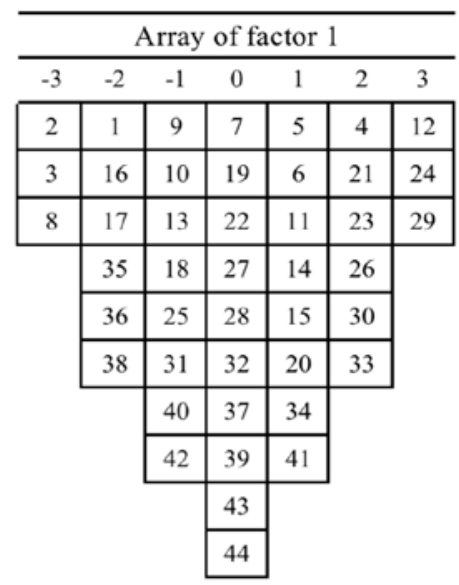

(a) Supervisory support

\begin{tabular}{|c|c|c|c|c|c|c|}
\hline \multicolumn{7}{|c|}{ Array of factor 3} \\
\hline-3 & -2 & -1 & 0 & 1 & 2 & 3 \\
\hline 5 & 4 & 1 & 8 & 12 & 3 & 6 \\
\hline 10 & 22 & 2 & 11 & 25 & 7 & 15 \\
\hline 38 & 24 & 13 & 17 & 28 & 9 & 40 \\
\hline & 37 & 14 & 18 & 29 & 19 & \\
\hline & 41 & 16 & 23 & 30 & 21 & \\
\hline & 42 & 20 & 26 & 31 & 34 & \\
\hline & & 35 & 27 & 32 & & \\
\hline & & 39 & 33 & 43 & & \\
\hline & & & 36 & & & \\
\hline & & & 44 & & & \\
\hline
\end{tabular}

(c) Cautiously stimulate

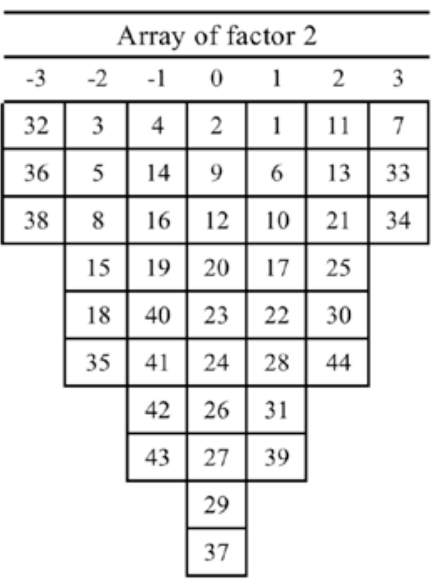

(b) Intensively investigate

(d) Proactively promote

Fig. 2. Factor arrays for four factors

\subsection{Perspective Interpretations}

The last step of Q methodology is the interpretations of the identified factors, which aims to uncover the perspectives of different stakeholder groups. Fig. 3 provides an overview of the four perspectives illustrated by the ratings in Fig. 2. The consensus statements of all perspectives are also addressed to unearth the common ground among the four perspectives. Participants' detailed explanations of their ratings collected during the exit interviews are quoted to ensure the accuracy of interpretations. 


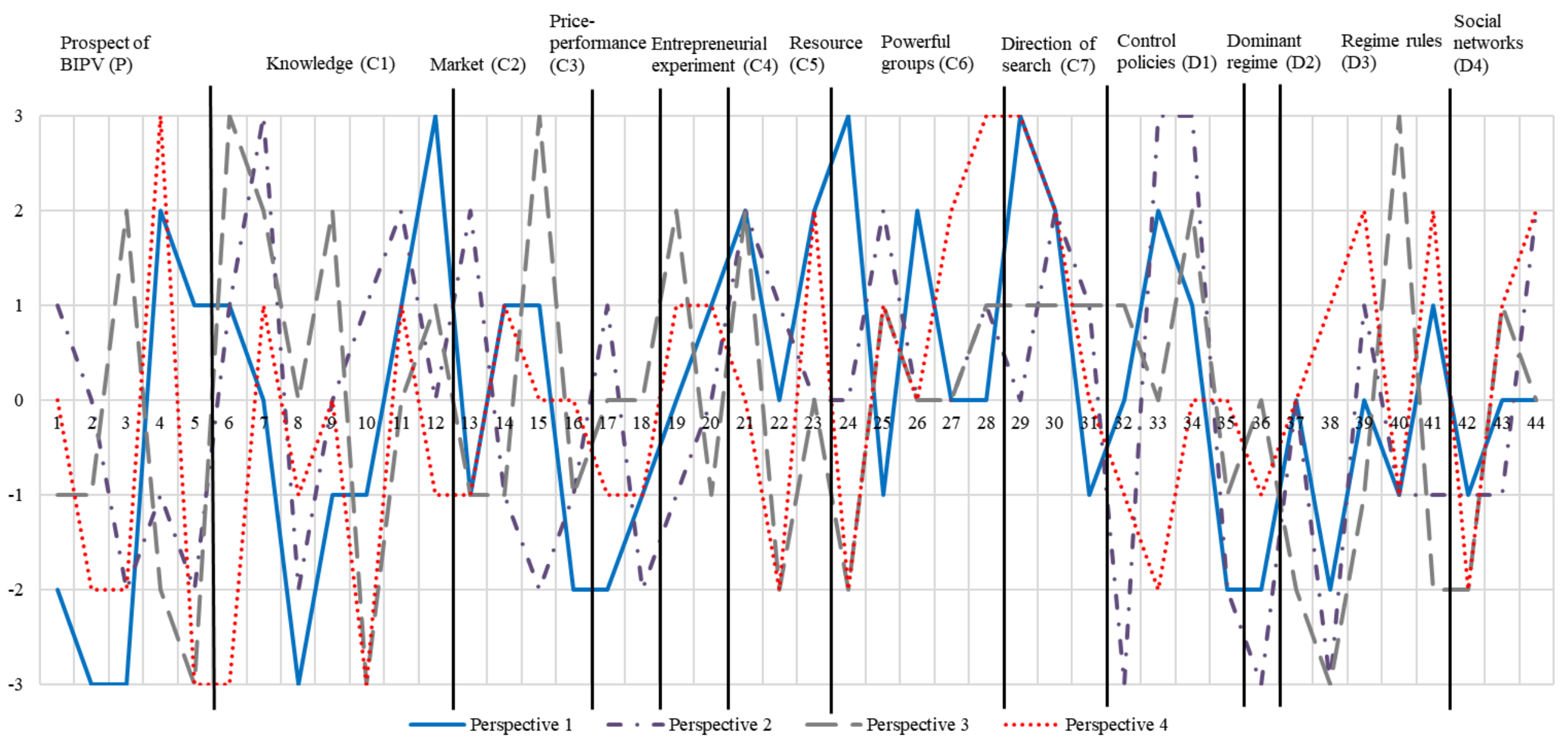

Fig. 3. Comparisons of the stakeholders' perspectives on the statements relevant to policy functions of BIPV 


\subsubsection{Perspective 1: Supervisory Support-BIPV has significant potential but it needs government} planning and industry standards

Results showed that perspective 1 accounts for $15 \%$ of the overall variance. Two stakeholders' viewpoints fall into this perspective, one from the designer group and one from the developer group (Table 4). Based on the factor array in Fig. 2, the main opinions expressed by this perspective was that construction projects with BIPV systems are having problems getting approval from governments [Statement 24] ${ }^{5}$ as there are neither clear signals that clarify the future planning [29] nor specific standards and codes related to BIPV in Singapore [12]. Nonetheless, they do believe that despite the problems of humid weather and low irradiance on facades in Singapore, BIPV has great potential to become the mainstream practice for energy generation [2, 3]. The problems could be eliminated if the government invest more in the R\&D of BIPV systems to search and design for the technology solution specifically for the Singapore context.

The members of this perspective view differently from the rest perspectives on the current status and means to promote BIPV in Singapore, which can be seen from the distinguishing statements (Fig 4). Both of the two interviewees stated that currently, BIPV in Singapore is still in a "grey area" since there is a lack of effective regulations [12] on it. They both discussed their past experiences of projects with BIPV systems disapproved by relative governmental agencies [24]. Perspective 1 believes that BIPV should be supported and emphasized since it is a very promising energy solution for Singapore [2, 5]. It is acknowledged that governmental bodies should be the major force to promote the adoption of BIPV instead of the private corporates $[25,26]$. And they suggested that the effective measure is to issue industry standard and codes, rather than establishing an explicit target of energy portfolio standard for renewable energy (e.g. 5\% of solar energy) in the long-term [31].

Regarding the policy functions for BIPV, Perspective 1 believes knowledge creation and diffusion [8, 12], support from power group e.g. governmental agencies [24] and the direction of search [29] are important policy functions for BIPV. By examining Fig 3, it could also be discovered that Perspective 1 values resource mobilization and control policies as well, as it moderately agrees with statement 21 and 33, which indicate that the government should establish an information platform of BIPV, e.g. providing reference guidelines for the best available technology of BIPV for the industry, and Singapore should gradually reduce the dependence on natural gas. Similarly, by strongly disagreeing with statements 2 and 3, as well as moderately agreeing with statement 4, Perspective 1 believes BIPV has the potential to become the mainstream practice in Singapore in the future. To summarize, Perspective 1 believes BIPV has significant potential but currently it is restricted by the lack of guidance and standards provided by the government. Therefore, the government needs to support BIPV by providing clear planning and issue industry standards for BIPV, complemented by the establishment of information platforms facilitating information exchange, and gradually controlling the use of natural gas.

\footnotetext{
${ }^{5}$ In the remaining sections, numbers with a square bracket indicate these numbers refer to statements in Table 2, rather than references. For instance, [29] means statement 29 in Table 2.
} 


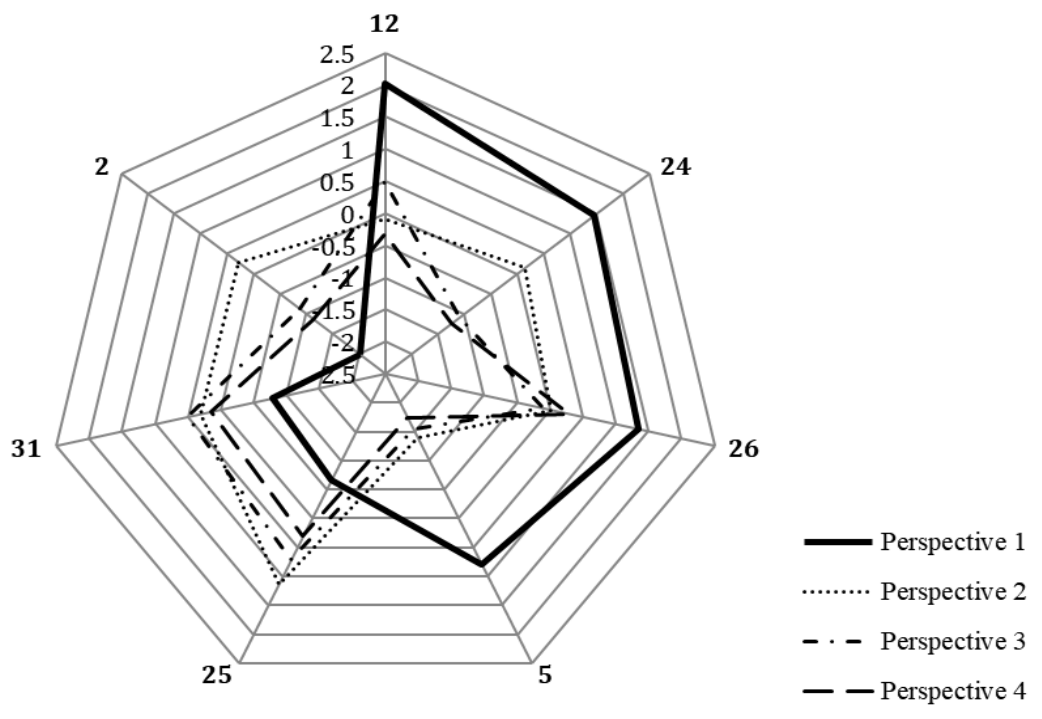

Fig. 4. Average loadings for the distinguishing statements of perspective 1

\subsubsection{Perspective 2: Intensively Investigate-It is unclear whether BIPV has potential, and thus currently the government should facilitate research on BIPV rather than providing incentives for BIPV adoption}

Four of the stakeholders fall into Perspective 2, which explains 19\% of the total variance. Among them, two participants were from the statutory board and the other two were from the designer group. According to the factor array (Fig. 2), this group recognizes the need for Singapore to reduce dependency on natural gas and looks for a solution from renewable energy sources like BIPV [33]. However, it concurs with the group that the lifecycle costs and benefits of BIPV is not thoroughly investigated enough for decision-making. Therefore more investigation is necessary before deciding to invest [7]. Before figuring out the potential of BIPV, some coercive measures and mandatory installation are not desirable [32,38]. Similarly, they pointed out that it is not practical to totally phase out natural gas, and the support for traditional energy sources should remain [34, 36].

The major differences of Perspective 2 with the rest perspectives lie in the following areas (Fig. 5). Firstly, stakeholders of Perspective 2 worried that although Singapore is located in the tropical area, the usable sunlight for BIPV systems is questionable due to the rainy and cloudy weather [2]. Besides, the potential problems of low energy conversion efficiency of BIPV systems, low approval rate by the local authorities of BIPV integrated projects and low acceptance from clients of BIPV buildings due to higher price would all hinder the future uptake of BIPV in Singapore $[10,13,24]$. Hence, the best solution for these problems is to further scrutinize the related benefits and costs of BIPV systems before making large-scale investments while retaining the continuous usage of traditional energy resources [7, 34]. Other possible measures considered inapplicable by this perspective include providing tax exemptions for BIPV developers, subsidies for domestic BIPV manufacturers and imposing a higher penalty for GHG emissions [15, 18, 32].

Regarding the policy functions for BIPV, Perspective 2 has a very struggled view of the use of control policies to control natural gas. On the one hand, Perspective 2 strongly agree with statement 33 that Singapore should gradually reduce the dependence on natural gas. On the other hand, Perspective 2 strongly disagree with statement 32 and 34, believing that Singapore should not impose a high penalty 
for greenhouse gas emission and currently it is not practical to phase out natural gas in Singapore. Therefore, Perspective 2 acknowledges the long-term energy challenge facing Singapore, but it does not willing to control the dominant fossil fuel, i.e. natural gas, which currently seems hardly to be replaced. By agreeing with statement 7 strongly and 11 moderately, Perspective 2 acknowledges the important role of knowledge creation and diffusion in BIPV. However, by moderately disagreeing with statement 15, Perspective 2 does not willing to increase market demand of BIPV by providing incentives to BIPV adopters. This illustrates that Perspective 2 believes before figuring out the potential of BIPV through knowledge creation and development, it is not appropriate to use other policy functions, such as market formation and control policies to promote BIPV.

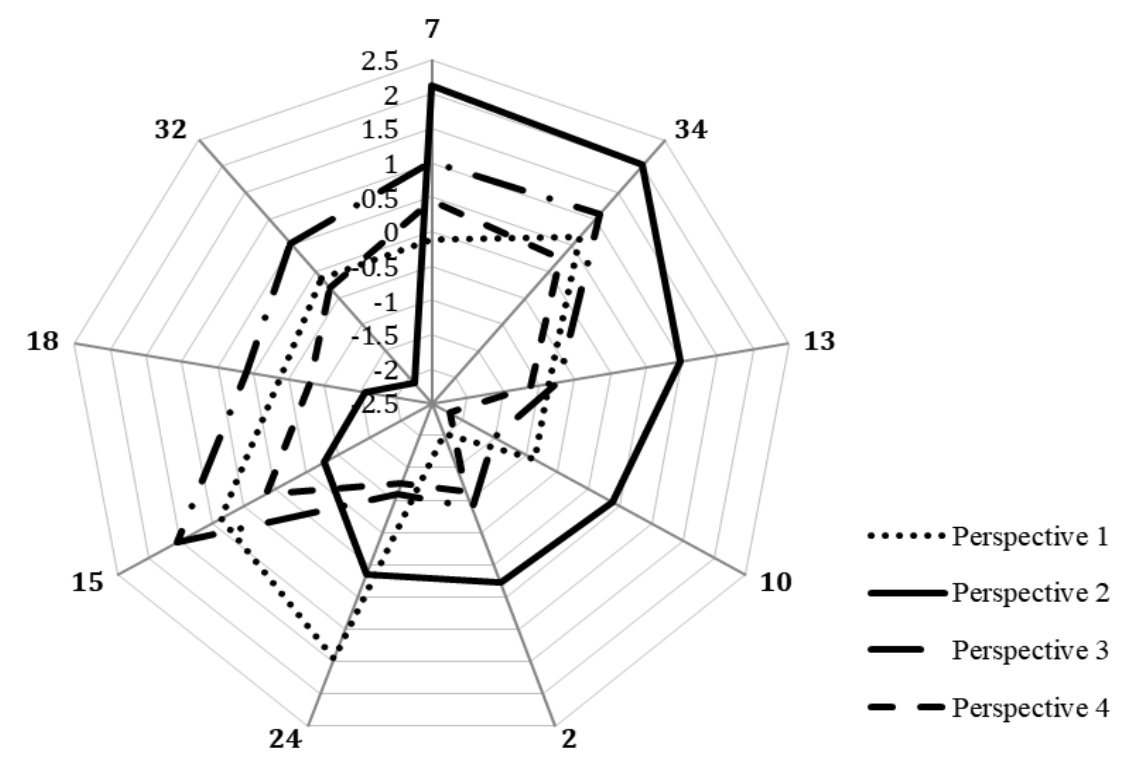

Fig. 5. Average loadings for the distinguishing statements of perspective 2

\subsubsection{Perspective 3: Cautiously Stimulate-Even though BIPV has limited potential, it is a sustainable option for energy and thus the government should provide incentives to stimulate this niche market}

Perspective 3 contains three stakeholders with two from the designer group and one from the developer group, and together they represent $15 \%$ of the overall variance (Table 4). As can be seen from the factor array (Fig. 2), stakeholders sharing perspective 3 believe BIPV has some potential even though the potential is limited, and as a sustainability innovation, the government should encourage this market through incentives. Specifically, Perspective 3 believes solar energy is not the only available renewable energy source in Singapore [5] and the R\&D capacity of BIPV in Singapore is weaker compared to other developed countries [6]. Considering the current situation, mandatory installation of BIPV system should be avoided [38]. However, Perspective 3 also believes it is wrong to wait for the technology improvements of BIPV before wide application [10]. As a stakeholder with this perspective mentioned that "technology will never be perfect, and we should adopt the technology as long as it is better and more sustainable than previous technologies". This contradicts with Perspective 2, as stakeholders with Perspective 2 moderately agree with statement 10 that "we should wait some time for technology improvements before wide application”. To improve the situation, Perspective 3 believes that the government should actively put more efforts in $R \& D$ and create increasing customer demand by providing labeling for the BIPV systems to owners and providing tax exemption for developers 
adopting BIPV in their projects or imposing smart meters in households so that consumers can see the actual benefit that BIPV systems bring [15, 40].

Fig. 6 shows the distinguishing statements for Perspective 3, which doubted that BIPV would become the mainstream energy source in the future because currently, solar energy constitutes a very small proportion $(<1 \%)$ of total generation, and it acknowledged the pressing need that Singapore should gradually reduce the dependency on tradition energy sources through withdrawing support for traditional electricity sources [3, 33, 36]. Perspective 3 also indicated that despite the fact that there are various types of BIPV systems in the local market [20], the present R\&D capacity of BIPV in Singapore is still weaker than other developed countries [6]. Thus, the government should establish comprehensive R\&D funding schemes or subsidies for the industry [9]. It is proposed by Perspective 3 that to change the current market rules, imposing smart meters to raise citizens' awareness toward BIPV is much more efficient than implementing total liberalization of the electricity market [37, 40]

Regarding the policy functions, Perspective 3 values knowledge creation through R\&D funding schemes, as well as establishing market niches by providing incentives to developers adopting BIPV. Perspective 3 also believe entrepreneurial experimentation is important, as it moderately agrees with statement 19 (Fig. 3) that "Singapore should stimulate entrepreneurship and bankability of small and medium-size firms in BIPV by providing low-interest loans, and venture capital”. Significant changes in regime rules are also important in driving the adoption of BIPV, reckoned by Perspective 3 which strongly believes that "imposing smart meters in households will increase the awareness of building occupants/owners in monitoring the export of potential of BIPV to the grid”. To summarize, Perspective 3 believes even though BIPV has limited potential, it needs to be promoted through various policy functions stimulating the players in this niche market, including firms involved in BIPV, property developers and users/households.

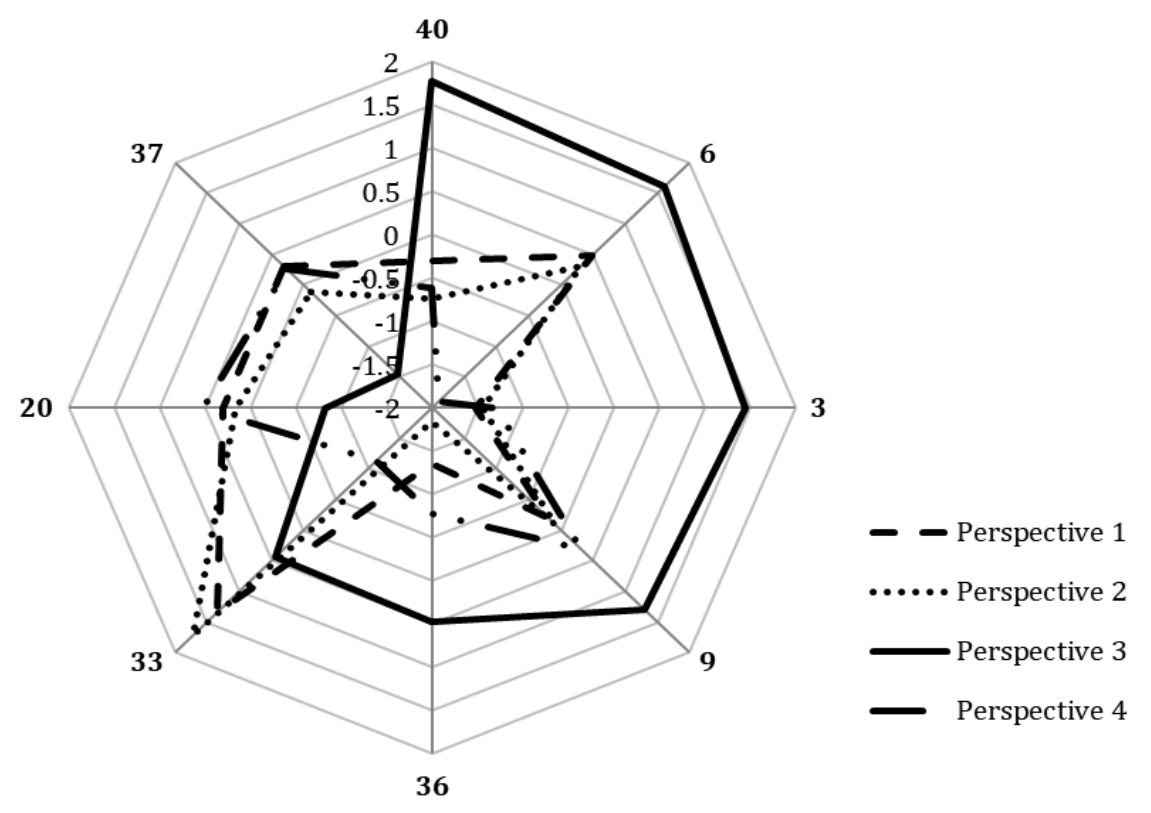

Fig. 6. Average loadings for the distinguishing statements of perspective 3 
4.2.4 Perspective 4: Proactively Promote-BIPV has huge potential and changing regime rules are more effective in promoting BIPV than providing incentives

Perspective 4 explains $14 \%$ of the total variance and all of the three stakeholders that match to this perspective were manufacturers. This perspective shows a highly optimistic view towards the development of BIPV in Singapore. They were convinced that although BIPV is not the only available form of solar technology to generate electricity, it is indeed the "best form" for Singapore to utilize solar energy considering the limited land area [4, 5]. In their opinion, neither the current R\&D capacity of BIPV in Singapore is weak, nor the present energy conversion efficiency of BIPV is low. It is just that the government should release clearer signals to guide the BIPV market and the private sectors should also participate in promoting BIPV [6, 10, 28, 29].

From the distinguishing statements for perspective 4 (Fig. 7), opposite views on BIPV could be found. They agreed that the current R\&D effort of BIPV in Singapore is strong and both the public and private sectors should take actions to foster the development of BIPV [6, 27, 28]. Moreover, Perspective 4 has the most positive view on the requirement of mandatory installation of BIPV on residential buildings [38]. All the other three perspectives moderately or strongly disagree with the mandatory installation of BIPV, while Perspective 4 slightly agrees with the mandatory installation. Interestingly, Perspective 4 does not agree that Singapore should reduce dependency on traditional energy source and the government needs to establish information platforms for BIPV [21, 33]. Stakeholders with this perspective explain that Singapore should reduce the dependence on natural gas not because natural gas will run out in the world one day, but because currently solar technologies, together with scientific design of buildings, could achieve net-zero energy consumption of buildings and thus solar technologies, such as BIPV, should become a reasonable and better choice for developers regardless of whether natural gas will run out or not.

Regarding the policy functions, surprisingly Perspective 4 does not place high importance to knowledge creation as stakeholders with Perspective 4 believe that Singapore's R\&D capacity of BIPV is strong enough even compared with other countries such as Germany [6]. But Perspective 4 does value resource mobilization as it moderately agrees that universities should offer more renewable energy-related degrees and graduate more young professionals with BIPV expertise. Perspective 4 highlights the importance of making significant changes in regime rules and social networks, as it believes that stronger energy efficiency policies for the industry should be developed and the government should provide avenues to disseminate knowledge and skills of BIPV to the stakeholders involved in the conventional energy market, to let the regime actors know more about BIPV. Interestingly, even though stakeholders with Perspective 4 strongly believe the potential of BIPV, they do not think that the government should provide monetary incentives for the BIPV players such as subsidies or tax exemptions for developers using BIPV and manufacturers producing BIPV systems, reflected by their rather neural and even negative ratings on the statements 9,15 and 18 . This could be explained by the following quotes from respondents: "I don't agree that BIPV should receive subsidies since it has immediate benefits so it does not need to be motivated by any kind of incentives" and "subsidies will hurt, rather than help, the R\&D of BIPV as manufacturers will only think about how to obtain the subsidies rather than making true technological improvements”. To summarize, Perspective 
4 has the most optimistic view on BIPV technology, and it believes that BIPV should be promoted by resource mobilization and changes in regime rules, e.g. stronger energy efficiency policies, rather than monetary incentives.

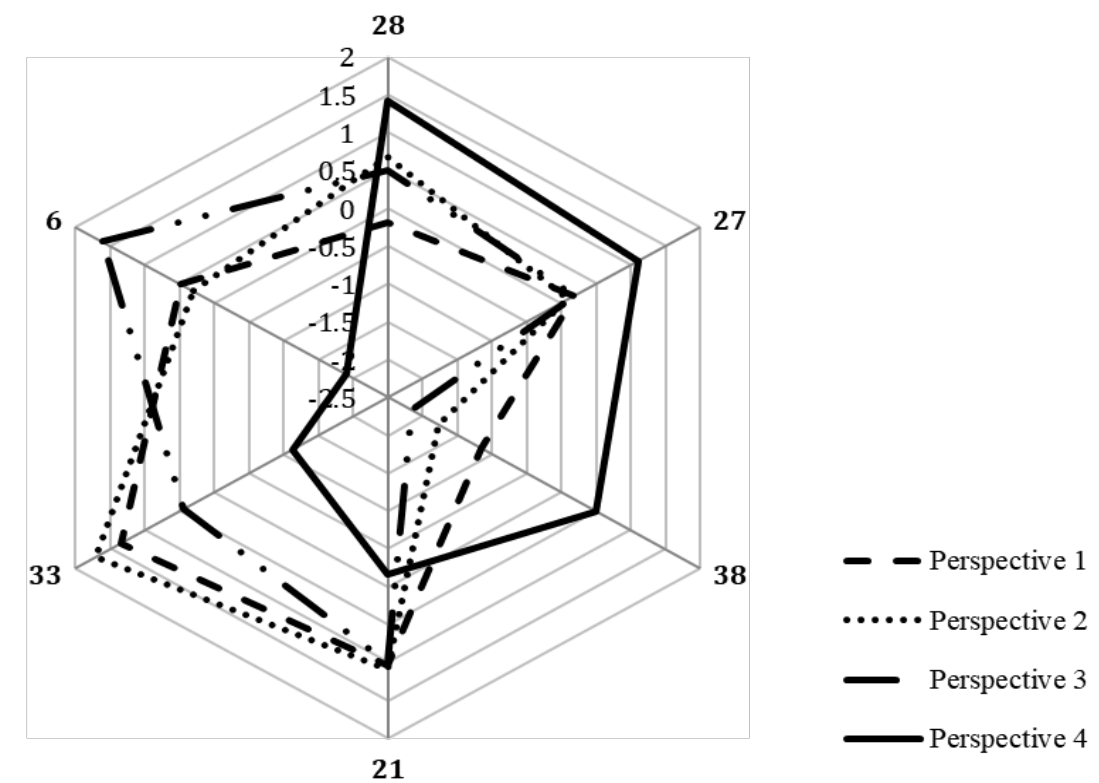

Fig. 7. Average loadings for the distinguishing statements of perspective 4

\subsection{The consensus among all perspectives}

Although the four perspectives have significant differences in perceiving BIPV in Singapore, they do have an agreement on certain aspects. As shown in Table 5, statement 30, 11, 16, 42 have similar average loadings across the four perspectives, which are consensus statements.

Table 5.

Consensus statements

\begin{tabular}{|c|c|c|c|c|c|}
\hline \multirow[t]{2}{*}{ No. } & \multirow[t]{2}{*}{ Statement } & \multicolumn{4}{|c|}{ Z-score } \\
\hline & & P1 & P2 & P3 & P4 \\
\hline 30 & $\begin{array}{l}\text { Singapore government needs to conduct a detailed potential } \\
\text { analysis of BIPV to know how much solar power could be } \\
\text { harvested }\end{array}$ & 0.98 & 1.19 & 0.82 & 1.24 \\
\hline 11 & $\begin{array}{l}\text { Singapore government should promote demonstration projects } \\
\text { and provide education programs to motivate the industry about } \\
\text { BIPV }\end{array}$ & 0.56 & 0.86 & 0.09 & 0.80 \\
\hline 16 & $\begin{array}{l}\text { Buildings with BIPV systems have a potentially large demand } \\
\text { as Singapore has a large group of residents who have highly } \\
\text { increased environmental awareness and wealth, thus willing } \\
\text { and able to purchase green projects despite the higher price }\end{array}$ & -0.86 & -0.52 & -0.82 & -0.11 \\
\hline 42 & $\begin{array}{l}\text { Singapore government has made significant progress to } \\
\text { promote renewable energy, and there is no need to conduct } \\
\text { structural changes in the government (e.g., establishing } \\
\text { interagency committee specifically focusing on renewable } \\
\text { energy) }\end{array}$ & -0.49 & -0.49 & -1.32 & -1.25 \\
\hline
\end{tabular}

On the one hand, four perspectives agreed that a more detailed analysis of BIPV should be conducted to understand better the overall capacity of solar energy that could be utilized [30]. To raise the public awareness of the great potential of BIPV, demonstration projects and education programs could be used [11]. There are some existing buildings in Singapore utilizing BIPV systems, such as the 7 \& 9 Tampines Grande Office Building which is the first commercial building installing BIPV panels in 
Singapore, the Zero-Energy Building owned by Building Construction Authority of Singapore, and the Tanjong Pagar Centre which is a mixed-use project. However, the number of existing buildings with BIPV systems installed is very small compared to the total number of buildings in Singapore, and more demonstration projects with BIPV systems need to be developed, perceived by the respondents. On the other hand, the respondents doubted whether there is a large demand from the customers towards BIPV due to the high price, and many stakeholders raised the opinion that most local consumers are more "cost-driven" rather than "environmentally concerned" [16]. In addition, the stakeholders proposed that certain structural changes in government could be made to expedite the development of BIPV in Singapore [42].

\section{Discussions}

\subsection{Theoretical contributions to innovation policy mix for energy transitions}

As aforementioned, Kivimaa et al. (2016) suggested in the analytical framework of policy mixes for sustainability transition (Table 1) that, ideally, policy mix for sustainability transitions should cover all the seven sub-functions of 'creative' (C1-C7) and four sub-functions of 'destructive' (D1-D4) so that the policy mix will be more likely to be effective in promoting successful sustainability transitions, such as the energy transition towards renewable energy sources. This study has applied the analytical framework as the theoretical basis for analyzing the deployment of BIPV in Singapore. The interview results showed that even though there are some agreements, different stakeholder groups held highly distinct perspectives towards the policy functions specified in the analytical framework, as shown in Table 6, which indicates the potential complexity in the actual application of the framework.

\section{Table 6}

Summary of research results

\begin{tabular}{|c|c|c|c|c|}
\hline Perspectives & $\begin{array}{l}\text { Supervisory } \\
\text { Support }\end{array}$ & $\begin{array}{l}\text { Intensively } \\
\text { Investigate }\end{array}$ & $\begin{array}{l}\text { Cautiously } \\
\text { Stimulate }\end{array}$ & $\begin{array}{l}\text { Proactively } \\
\text { Promote }\end{array}$ \\
\hline Stakeholders & $\begin{array}{l}1 \text { Designer } \\
1 \text { Developer }\end{array}$ & $\begin{array}{l}2 \text { Designers } \\
2 \text { Statutory Boards }\end{array}$ & $\begin{array}{l}2 \text { Designer } \\
1 \text { Developers }\end{array}$ & 4 PV Manufacturers \\
\hline $\begin{array}{l}\text { Divergent } \\
\text { Opinions }\end{array}$ & $\begin{array}{l}\text { - BIPV has } \\
\text { significant potential } \\
\text { in SG } \\
\text { - Needs government } \\
\text { planning and } \\
\text { industry standards }\end{array}$ & $\begin{array}{l}\text { - } \text { BIPV might be } \\
\text { suitable in SG } \\
\text { - Need more } \\
\text { investigations } \\
\text { before implement }\end{array}$ & $\begin{array}{l}\text { - } \text { BIPV has } \\
\text { limited potential } \\
\text { in SG } \\
\text { - Need incentives } \\
\text { to stimulate the } \\
\text { market }\end{array}$ & $\begin{array}{l}\text { - } \text { BIPV is the best form } \\
\text { of using solar energy } \\
\text { in SG } \\
\text { - Need to change } \\
\text { regime rules }\end{array}$ \\
\hline Consensus & \multicolumn{4}{|c|}{$\begin{array}{l}\text { - More detailed analyses on BIPV are needed } \\
\text { - Demonstration projects \& education programs to raise public awareness } \\
\text { - Low demand by occupants due to the high price } \\
\text { - Certain structural changes needed to promote BIPV }\end{array}$} \\
\hline
\end{tabular}

For instance, this study reveals that stakeholders have different perspectives on BIPV, with some stakeholders believing the potential of BIPV while others hardly recognize its importance. This echoes our previous study Lu et al. (2019). Even for the stakeholders acknowledging the importance of BIPV, some stakeholders believe BIPV should receive government subsidies and incentives while others believe the government should change the regime rules rather than simply providing monetary incentives. How to cater for the various stakeholders' different perspectives with innovation policy mix? With the restricted governmental resources such as incentives and human resources, which creative or 
destructive policy functions should be prioritized so that the sustainability transitions could be facilitated in the most effective way? This study has revealed these fundamental questions of innovation policy mix, which have not been addressed by the framework proposed by Kivimaa et al. (2016).

Therefore, it is proposed that the analytical framework could be improved in the following two areas. Firstly, the current framework proposed only the ideal policy functions without taking into account the divergent opinions and perspectives from various stakeholders involved in sustainability transitions, which downgrades the effectiveness of the framework as ultimately, the success of a transition is dependent on the close collaboration and support from various industry players (Gan et al., 2018; Wu et al., 2018). Hence, it is advised that the future development of the framework could link the policy functions of innovation policy mix with the major types of perspectives on sustainability transitions existed in stakeholders, so that the policy functions could be more targeted on stakeholders with specific perspectives. For instance, this study has identified stakeholders' four perspectives on BIPV in Singapore, which is influenced by the perceptions of 1) whether BIPV has significant potential for energy transition and 2) what policy functions are important for empowering BIPV. The future framework of innovation policy mix could similarly link the policy functions to the stakeholders who highly, moderately or do not believe the importance of sustainability innovations, thereby more effectively targeting on different stakeholders' perspectives to facilitate stakeholder collaboration. To propose such a framework, more studies need to be conducted to investigate stakeholders' perspectives on other energy innovations, e.g. micro wind turbines, in different social contexts e.g. developed v.s. developing countries, to see whether stakeholders' perspectives on various energy innovations in various countries show similar patterns so that a unified framework of innovation policy mix could be developed to link preferred policy functions with specific perspectives.

Similarly, the framework could be further specified to guide the policies to be launched in different stages of sustainability transitions. The uptake of BIPV technologies is ultimately determined by firms in the construction industry, whose sustainability attitudes and performance are constantly changing (Chang et al., 2017a; Chang et al., 2018). As the focus of various transition stages is constantly changing, it is difficult for a static framework to guide the dynamic transition process. Future studies could be conducted to review the innovation policies for energy innovations that were launched in various countries and their effects on the different stages of energy transitions. The findings could then be categorized and integrated into a framework that could illustrate the priorities of policy functions for the different stages of an energy transition.

\subsection{Validity, reliability and generalizability}

The assessment of the validity, reliability and generalizability of Q methodology is systemically illustrated by Valenta et al. (1997). As explained by Valenta et al. (1997), content validity of Q-sample should be addressed by thorough literature review and by eliciting expert advice. This study developed the initial Q-sample based on an extensive literature review, and subsequently invited six experts from either the Energy Studies Institute of National University of Singapore, or the Solar Energy Research Institute of Singapore to provide comments and suggestions to improve the initial Q-sample. Therefore, this study adequately addressed the content validity requirements. The construct (item) validity 
understood in traditional survey research, however, is not applicable to Q methodology, which is also explained by Valenta et al. (1997). The purpose of Q methodology is to uncover respondents' divergent opinions on an issue rather than statistically measuring respondents' level of awareness or performance on a measure, and therefore the concept of construct validity is not applicable to Q methodology.

The reliability of Q methodology has been tested and subsequently proven by previous test-retest studies. Dennis (1992) reported that administrating the same Q sample to the same individuals at two time points resulted in a correlation coefficient of 0.8 or higher. Fairweather (1981) reported a similar finding that the test-retest reliability of $\mathrm{Q}$ methodology was around 0.9 . As the reliability of $\mathrm{Q}$ methodology has been proven decades ago, the reliability of studies utilizing Q methodology could be ensured if the studies rigorously follow the standard procedures of conducting Q methodology (Akhtar-Danesh et al., 2008). Each step of this study, from the identification of Q samples and selection of P sets, to Q sorting and factor analysis, strictly follows the standard procedure of Q methodology, and thus the reliability of this study is ensured.

As Q methodology identifies representative perspectives based on a small sample of respondents who are not randomly selected in a population, the findings of studies employing Q methodology cannot be statistically generalized to a larger population (Valenta et al., 1997). It is expected that the population which the studied sample was drawn from could potentially have other perspectives. This, however, does not diminish the value of $\mathrm{Q}$ methodology. As an exploratory method, $\mathrm{Q}$ methodology aims to uncover the representative perspectives in the population which are meaningful for theory development and policy making. For instance, this study identifies that four distinct perspectives of BIPV exist in the investigated 15 respondents. These identified perspectives have demonstrated the large variance existing in stakeholders' preferences for BIPV policies, which indicates that the current theoretical framework of innovation policy mix needs to consider this variance and complexity. If a future study investigating a larger population revealed other perspectives, the results would strengthen, rather than weaken, the results of this study, as the future study further demonstrates the large variance of opinions in the population.

Therefore, even though this study investigated the policy functions for BIPV by taking Singapore as an example, the results have implications to other countries, especially those countries where BIPV technologies have not been widely diffused in the building industry such as China and Australia. Specifically, this study indicates that stakeholders have four distinct policy preferences for BIPV, ranging from "intensively investigate" and "cautiously stimulate" to "supervisory support" and "proactively promote", determined by the respondents' attitudes towards BIPV and their preferred policy functions. It is expected that in other countries, stakeholders could also have different opinions on BIPV, with some stakeholders being more cautious about while others are convinced of the potential of BIPV. Therefore, the identified perspectives in this study could be referred by other countries to better understand the diversity of opinions on BIPV. However, it is important to note that even though the diversity of opinions is to be expected in various countries, the percentages of stakeholders with the similar opinions could be different in various countries, due to the different development stages of BIPV in different countries. For instance, compared to Singapore, Germany has a higher penetration rate of BIPV technologies in the built environment (Osseweijer et al., 2018) and therefore, could have a 
higher percentage of stakeholders embracing BIPV. Therefore, this study has policy implications particularly for countries at the initial development stage of BIPV similar to Singapore. Future studies should investigate the stakeholders' preferred policy functions for BIPV in countries where BIPV technology is relatively mature such as Germany. This actually echoes to the previous section where this study suggests the framework of innovation policy mix should incorporate the time dimension to guide the policies to be launched in different stages of sustainability transitions.

\section{Conclusion and policy implications}

\subsection{Conclusion}

This study employed the innovation policy mix approach to investigate the stakeholders' perspectives on the prospects of and policy functions for BIPV in Singapore based on Q methodology. A total of 15 key stakeholders from four groups, including BIPV manufacturers, developers, designers and statutory boards, participated in this study. By using Q methodology, four major perspectives were identified from these stakeholders, namely, 'Perspective 1: Supervisory Support', "Perspective 2: Intensively Investigate', "Perspective 3: Cautiously Stimulate' and "Perspective 4: Proactively Promote'.

Stakeholders with Perspective 1 believed that with the issue of industry planning and standards, BIPV has significant potential to become the future mainstream energy source in Singapore. Perspective 2 believed that the possibility of BIPV as the mainstream energy technology is not absolute and before ensuring its potential, the government should not promote the adoption of BIPV. Perspective 3 foresaw various problems associated with BIPV and thus believes the potential of BIPV is limited. But as a sustainable alternative to natural gas, BIPV should still be promoted by the government through incentives. On the contrary, stakeholders with Perspective 4 not only perceived BIPV as the best form to exploit solar energy in Singapore, but also convinced that regime rules need to be changed to proactively promote BIPV.

Despite the differences across the identified perspectives, participants do concur that in order to support BIPV development, more in-depth analyses regarding the performance and cost-benefits of BIPV should be conducted. The problems of low public awareness and acceptance towards BIPV could be alleviated through more demonstration projects. In addition, inter-agency committee targeting the assessment of BIPV projects could be formed to further promote BIPV.

\subsection{Policy implications}

The divergent opinions and consensuses towards the deployment of BIPV in Singapore held by the key stakeholders were uncovered, which provides significant policy implications.

From the consensus statements identified, urgent actions are needed to conduct thorough and in-depth studies on the energy generation potential and cost-benefit analysis of BIPV, which could either be lead by the governmental bodies such as the Singapore Building and Construction Authority (BCA), or by government-funded research institutes such as the Solar Energy Research Institute of Singapore. Through these studies, the obtainable solar power, the available space to install BIPV systems in Singapore as well as the cost of this BIPV movement could be unveiled, based on which the next step of promoting BIPV could be considered and planned. Secondly, more BIPV demonstration projects 
could be constructed for educational purposes and to raise the public awareness of BIPV. As the existing ones located at the areas that are hardly accessible to the public, future demonstration projects should be constructed in central districts and exhibited to both the industry players and the general public. Last but not least, stakeholders agreed that structural changes within the government are needed to further promote renewable energy. For instance, the inter-agency committee could be established to specifically targeting on granting approval toward potential BIPV projects.

Regarding to the divergent opinions of different perspectives, it can be seen that the BIPV manufacturers had the most optimistic views (Perspective 3) towards the future deployment of BIPV, while the government officials and some designers took a skeptical attitude by believing that BIPV should be deployed after further investigation and improvement (Perspective 2). To facilitate mutual understanding and stakeholder collaboration, an information exchange platform connecting different stakeholders need to be set up, so that the various stakeholders could communicate their perspectives on various aspects, e.g. the possibility of using BIPV to become the mainstream practice of energy generation in Singapore, the R\&D capability of Singapore, and the cost-benefit development trend of installing BIPV systems. It is pressing for the relevant stakeholders to form a shared vision of BIPV based on a scientific investigation of the potential of BIPV so that a comprehensive strategic plan of BIPV for Singapore could be developed.

\section{Acknowledgment}

The study was supported by the project: "Holistic life-cycle cost analysis and real-world test bedding for Building Integrated Photovoltaics (BIPV) facades”, funded by Singapore's Ministry of National Development - Sino-Singapore Tianjin Eco-City Administrative Committee Green Building Related Research and Development Programme and the Building and Construction Authority of Singapore (BCA).

\section{References}

Akhtar-Danesh, N., Baumann, A., \& Cordingley, L. (2008). Q-methodology in nursing research: a promising method for the study of subjectivity. Western Journal of Nursing Research, 30(6), 759-773.

Alkemade, F., Hekkert, M. P., \& Negro, S. O. (2011). Transition policy and innovation policy: Friends or foes? Environmental Innovation and Societal Transitions, 1(1), 125-129.

Aristizabal, A., \& Gordillo, G. (2008). Performance monitoring results of the first grid-connected BIPV system in Colombia. Renewable Energy, 33(11), 2475-2484.

Azadian, F., \& Radzi, M. A. M. (2013). A general approach toward building integrated photovoltaic systems and its implementation barriers: A review. Renewable and Sustainable Energy Reviews, 22, 527-538.

Barry, J., \& Proops, J. (1999). Seeking sustainability discourses with Q methodology. Ecological Economics, 28(3), 337-345.

Borrás, S., \& Edquist, C. (2013). The choice of innovation policy instruments. Technological Forecasting and Social Change, 80(8), 1513-1522.

Breukers, S. (2006). Changing institutional landscapes for wind power implementation. A geographical comparison of institutional capacity building: The Netherlands, England and North-Rhine 
Westphalia. In: Amsterdam: University of Amsterdam.

Brown, S., Danielson, S., \& Exel, J. (2015). Overly ambitious critics and the Medici Effect: a reply to Kampen and Tamás. Quality \& Quantity, 49(2).

Brown, S. R. (1996). Q methodology and qualitative research. Qualitative Health Research, 6(4), 561-567.

Chang, R.-d., Soebarto, V., Zhao, Z.-y., \& Zillante, G. (2016). Facilitating the transition to sustainable construction: China's policies. Journal of Cleaner Production, 131, 534-544.

Chang, R.-d., Zuo, J., Soebarto, V., Zhao, Z.-y., Zillante, G., \& Gan, X.-l. (2017a). Discovering the transition pathways toward sustainability for construction enterprises: Importance-performance analysis. Journal of Construction Engineering and Management, 143(6), 04017013.

Chang, R.-D., Zuo, J., Zhao, Z.-Y., Soebarto, V., Lu, Y., Zillante, G., \& Gan, X.-L. (2018). Sustainability attitude and performance of construction enterprises: A China study. Journal of Cleaner Production, 172, 1440-1451.

Chang, R., Zillante, G., Soebarto, V., \& Zhao, Z. (2015). Transition to a Sustainability-Oriented Construction Industry in China: A Critical Analysis from the Multi-Level Perspective. In ICCREM 2015 (pp. 361-368).

Chang, R. d., Zuo, J., Zhao, Z. y., Soebarto, V., Zillante, G., \& Gan, X. l. (2017b). Approaches for transitions towards sustainable development: status quo and challenges. Sustainable Development, 25(5), 359-371.

Chen, W., \& Wei, P. (2018). Socially optimal deployment strategy and incentive policy for solar photovoltaic community microgrid: A case of China. Energy Policy, 116, 86-94.

Cumming, D. J., Leboeuf, G., \& Schwienbacher, A. (2017). Crowdfunding cleantech. Energy Economics, 65, 292-303.

Cuppen, E., Breukers, S., Hisschemöller, M., \& Bergsma, E. (2010). Q methodology to select participants for a stakeholder dialogue on energy options from biomass in the Netherlands. Ecological Economics, 69(3), 579-591.

Dennis, K. (1992). Commentary: looking at reliability and validity through Q-colored glasses. Operant Subjectivity, 16, 37-44.

Dryzek, J. S., \& Niemeyer, S. (2008). Discursive representation. American Political Science Review, 102(4), 481-493.

Eden, S., Donaldson, A., \& Walker, G. (2005). Structuring subjectivities? Using Q methodology in human geography. Area, 37(4), 413-422.

Ellis, G., Barry, J., \& Robinson, C. (2007). Many ways to say 'no', different ways to say 'yes': Applying Q-Methodology to understand public acceptance of wind farm proposals. Journal of Environmental Planning and Management, 50(4), 517-551. doi:10.1080/09640560701402075

Fairweather, J. (1981). Reliability and validity of Q-method results: Some empirical evidence. Operant Subjectivity, 5(1), 2-16.

Falcone, P. M., Lopolito, A., \& Sica, E. (2017). Policy mixes towards sustainability transition in the Italian biofuel sector: Dealing with alternative crisis scenarios. Energy Research \& Social Science, 33, 105-114.

Ferrara, C., Wilson, H., \& Sprenger, W. (2016). Fraunhofer Institute for Solar Energy Systems, Freiburg, Germany. The Performance of Photovoltaic (PV) Systems: Modelling, Measurement and Assessment, 235. 
Gan, X., Chang, R., \& Wen, T. (2018). Overcoming barriers to off-site construction through engaging stakeholders: A two-mode social network analysis. Journal of Cleaner Production, 201, 735-747.

Geels, F. W. (2002). Technological transitions as evolutionary reconfiguration processes: a multi-level perspective and a case-study. Research Policy, 31(8), 1257-1274.

Geels, F. W. (2004). From sectoral systems of innovation to socio-technical systems: Insights about dynamics and change from sociology and institutional theory. Research Policy, 33(6), 897-920.

Geels, F. W. (2006). Co-evolutionary and multi-level dynamics in transitions: the transformation of aviation systems and the shift from propeller to turbojet (1930-1970). Technovation, 26(9), 999-1016.

Global Industry Analysts. (2015). The global building integrated photovoltaics (BIPV) market 2015-2019. Retrieved from https://www.technavio.com/report/global-building-integrated-photovoltaic-bipv-market-2015-2019.

Grin, J., Rotmans, J., \& Schot, J. (2010). Transitions to sustainable development: new directions in the study of long term transformative change: Routledge.

Hammond, G. P., Harajli, H. A., Jones, C. I., \& Winnett, A. B. (2012). Whole systems appraisal of a UK Building Integrated Photovoltaic (BIPV) system: energy, environmental, and economic evaluations. Energy Policy, 40, 219-230.

Heinstein, P., Ballif, C., \& Perret-Aebi, L.-E. (2013). Building integrated photovoltaics (BIPV): review, potentials, barriers and myths. Green, 3(2), 125-156.

Housing \& Development Board. (2018). SolarNova Programme. Retrieved from https://www.hdb.gov.sg/cs/infoweb/about-us/our-role/smart-and-sustainable-living/solarnova-page.

Howard, R. J., Tallontire, A. M., Stringer, L. C., \& Marchant, R. A. (2016). Which “fairness”, for whom, and why? An empirical analysis of plural notions of fairness in Fairtrade Carbon Projects, using Q methodology. Environmental Science \& Policy, 56, 100-109.

Hugé, J., Velde, K. V., Benitez-Capistros, F., Japay, J. H., Satyanarayana, B., Ishak, M. N., . . Koedam, N. (2016). Mapping discourses using Q methodology in Matang Mangrove Forest, Malaysia. Journal of Environmental Management, 183, 988-997.

International Energy Agency. (2017). World Energy Statistics and Balances 2017. Retrieved from https://webstore.iea.org/world-energy-statistics-and-balances.

Jaung, W., Putzel, L., Bull, G. Q., \& Kozak, R. (2016). Certification of forest watershed services: AQ methodology analysis of opportunities and challenges in Lombok, Indonesia. Ecosystem Services, 22, 51-59.

Kaiser, H. F. (1960). The application of electronic computers to factor analysis. Educ. Psychol. Meas., 20(141-151).

Kemp, R., Schot, J., \& Hoogma, R. (1998). Regime shifts to sustainability through processes of niche formation: the approach of strategic niche management. Technology analysis \& strategic management, 10(2), 175-198.

Kim, K. Y., \& Lee, B. G. (2015). Marketing insights for mobile advertising and consumer segmentation in the cloud era: AQ-R hybrid methodology and practices. Technological Forecasting and Social Change, 91, 78-92.

Kivimaa, P., Kangas, H.-L., \& Lazarevic, D. (2017). Client-oriented evaluation of 'creative destruction'in policy mixes: Finnish policies on building energy efficiency transition. Energy Research \& Social Science, 33, 115-127. 
Kivimaa, P., \& Kern, F. (2016). Creative destruction or mere niche support? Innovation policy mixes for sustainability transitions. Research Policy, 45(1), 205-217.

Kwon, T.-h. (2012). Strategic niche management of alternative fuel vehicles: A system dynamics model of the policy effect. Technological Forecasting and Social Change, 79(9), 1672-1680.

Lachman, D. A. (2013). A survey and review of approaches to study transitions. Energy Policy, 58, 269-276.

Lanahan, L., \& Feldman, M. P. (2015). Multilevel innovation policy mix: A closer look at state policies that augment the federal SBIR program. Research Policy, 44(7), 1387-1402.

Lilliestam, J., Barradi, T., Caldés, N., Gomez, M., Hanger, S., Kern, J., . . W Wang, Z. (2018). Policies to keep and expand the option of concentrating solar power for dispatchable renewable electricity. Energy Policy, 116, 193-197.

Lim, C. H., Kamaruzzaman, S., \& Yusof, S. (2009). Public Response to Residential Building Integrated Photovoltaic System (BIPV) in Kuala Lumpur Urban Area. IASME/WSEAS International Conference on Energy \& Environment.

Lu, Y., Chang, R., \& Lim, S. (2018). Crowdfunding for solar photovoltaics development: A review and forecast. Renewable Sustainable Energy Reviews, 93, 439-450.

Lu, Y., Chang, R., Shabunko, V., \& Yee, A. T. L. (2019). The implementation of building-integrated photovoltaics in Singapore: drivers versus barriers. Energy, 168, 400-408.

Magro, E., \& Wilson, J. R. (2013). Complex innovation policy systems: Towards an evaluation mix. Research Policy, 42(9), 1647-1656.

Markard, J., Raven, R., \& Truffer, B. (2012). Sustainability transitions: An emerging field of research and its prospects. Research Policy, 41(6), 955-967.

Maturi, L., Belluardo, G., Moser, D., \& Del Buono, M. (2014). BiPV system performance and efficiency drops: overview on PV module temperature conditions of different module types. Energy Procedia, 48, 1311-1319.

Meelen, T., \& Farla, J. (2013). Towards an integrated framework for analysing sustainable innovation policy. Technology Analysis \& Strategic Management, 25(8), 957-970.

Osseweijer, F. J., Van Den Hurk, L. B., Teunissen, E. J., \& van Sark, W. G. (2018). A comparative review of building integrated photovoltaics ecosystems in selected European countries. Renewable and Sustainable Energy Reviews, 90, 1027-1040.

Pagliaro, M., Ciriminna, R., \& Palmisano, G. (2010). BIPV: merging the photovoltaic with the construction industry. Progress in Photovoltaics: Research and Applications, 18(1), 61-72.

Peng, C., Huang, Y., \& Wu, Z. (2011). Building-integrated photovoltaics (BIPV) in architectural design in China. Energy and Buildings, 43(12), 3592-3598.

Quitzow, R. (2015a). Assessing policy strategies for the promotion of environmental technologies: A review of India's National Solar Mission. Research Policy, 44(1), 233-243.

Quitzow, R. (2015b). Dynamics of a policy-driven market: The co-evolution of technological innovation systems for solar photovoltaics in China and Germany. Environmental Innovation and Societal Transitions, 17, 126-148.

Raadgever, G., Mostert, E., \& Van De Giesen, N. (2008). Identification of stakeholder perspectives on future flood management in the Rhine basin using Q methodology. Hydrol. Earth Syst. Sci., 12, 1097-1109, 2008.

Rip, A., \& Kemp, R. (1998). Technological change: Battelle Press. 
Rogge, K. S., \& Reichardt, K. (2016). Policy mixes for sustainability transitions: An extended concept and framework for analysis. Research Policy, 45(8), 1620-1635.

Schmolck, P., \& Atkinson, J. (2014). PQMethod.

Silvius, A. G., Kampinga, M., Paniagua, S., \& Mooi, H. (2017). Considering sustainability in project management decision making; An investigation using Q-methodology. International Journal of Project Management, 35(6), 1133-1150.

Solar Energy Research Institute of Singapore. (2018). Solar Economics Handbook. Retrieved from http://www.solar-repository.sg/singapore-pv-market.

Sozer, H., \& Elnimeiri, M. (2007). Critical factors in reducing the cost of building integrated photovoltaic (BIPV) systems. Architectural Science Review, 50(2), 115-121.

Tabakovic, M., Fechner, H., van Sark, W., Louwen, A., Georghiou, G., Makrides, G., . . . Betz, S. (2017). Status and Outlook for Building Integrated Photovoltaics (BIPV) in Relation to Educational needs in the BIPV Sector. Energy Procedia, 111, 993-999.

Valenta, A. L., \& Wigger, U. (1997). Q-methodology: definition and application in health care informatics. Journal of the American Medical Informatics Association, 4(6), 501-510.

Van Eijck, J., \& Romijn, H. (2008). Prospects for Jatropha biofuels in Tanzania: an analysis with strategic niche management. Energy Policy, 36(1), 311-325.

Van Exel, J., \& De Graaf, G. (2005). Q methodology: A sneak preview. Retrieved January, 24, 2009.

Verbong, G., Christiaens, W., Raven, R., \& Balkema, A. (2010). Strategic Niche Management in an unstable regime: Biomass gasification in India. Environmental Science \& Policy, 13(4), 272-281.

Weber, K. M., \& Rohracher, H. (2012). Legitimizing research, technology and innovation policies for transformative change. Research Policy, 41(6), 1037-1047.

Wu, G., Qiang, G., Zuo, J., Zhao, X., \& Chang, R. J. S. (2018). What are the Key Indicators of Mega Sustainable Construction Projects?-A Stakeholder-Network Perspective. 10(8), 2939.

Xue, Y., You, J., Liang, X., \& Liu, H.-C. (2016). Adopting strategic niche management to evaluate EV demonstration projects in China. Sustainability, 8(2), 142.

Yang, R. J. (2015). Overcoming technical barriers and risks in the application of building integrated photovoltaics (BIPV): hardware and software strategies. Automation in Construction, 51, 92-102.

Yuan, X., Wang, X., \& Zuo, J. (2013). Renewable energy in buildings in China-A review. Renewable and Sustainable Energy Reviews, 24, 1-8.

Zeeuw, H. v. d. (2011). Manual for BIPV Projects. Odersun Publication.

Zhao, Z.-Y., Chang, R.-D., \& Chen, Y.-L. (2016a). What hinder the further development of wind power in China?-A socio-technical barrier study. Energy Policy, 88, 465-476.

Zhao, Z.-Y., Chen, Y.-L., \& Chang, R.-D. (2016b). How to stimulate renewable energy power generation effectively?-China's incentive approaches and lessons. Renewable Energy, 92, 147-156.

Zomer, C., Nobre, A., Reindl, T., \& Rüther, R. (2016). Shading analysis for rooftop BIPV embedded in a high-density environment: A case study in Singapore. Energy and Buildings, 121, 159-164. 